\title{
THE NATURE OF THE BEAST: CONODONTS AS ANIMALS
}

PURNELL, Mark A., Department of Geology, University of Leicester, University Road, Leicester LE1 7RH, UK

After almost a century and a half conodonts have reluctantly relinquished the title of 'most mysterious fossils'. Now known to be vertebrates, conodonts are no longer enigmatic but new information regarding their anatomy, functional morphology and affinities is ensuring that they remain just as fascinating and controversial. Within this developing biological framework it is finally possible, without resorting to unconstrained speculation, to determine what conodonts were like as living animals.

The function of conodont elements has been the subject of almost as much debate as hypotheses of affinity; until the discovery of unequivocal body traces, even the orientation and position of the elements within the organism were unknown. But with the recognition that the conodont apparatus lay in the head of the animal only two functional hypotheses remain: the elements operated either as a filtering device in a suspension feeding animal, or as a raptorial array and teeth. The recent discovery of microwear patterns produced in vivo on the functional surfaces of the elements provides unequivocal evidence that they acted as slicing and crushing teeth. Slicing as a means of food breakdown indicates that conodonts were macrophagous, and variability in microwear between species indicates that different taxa ate different food. The anterior $\mathrm{S}$ element array probably grasped food, but it has recently been suggested that it may represent a denticulate pharyngeal apparatus. The resolution of these uncertainties has important implications, not only for feeding mechanisms in conodonts, but also for their phylogenetic position within the vertebrates.

The few fossils that preserve conodont soft parts clearly demonstrate that conodonts had eyes and that they were large relative to the size of the body. But does this mean that they could see well? In absolute terms conodont eyes are small, probably close to the minimum size threshold for a functional vertebrate eye, but their size does compare with that of other small vertebrates. This, together with the presence of extrinsic eye musculature, suggests that conodonts had good vision, probably comparable to that of lampreys.

Although soft tissue evidence is limited, the trunk outlines of the conodont animal fossils from the

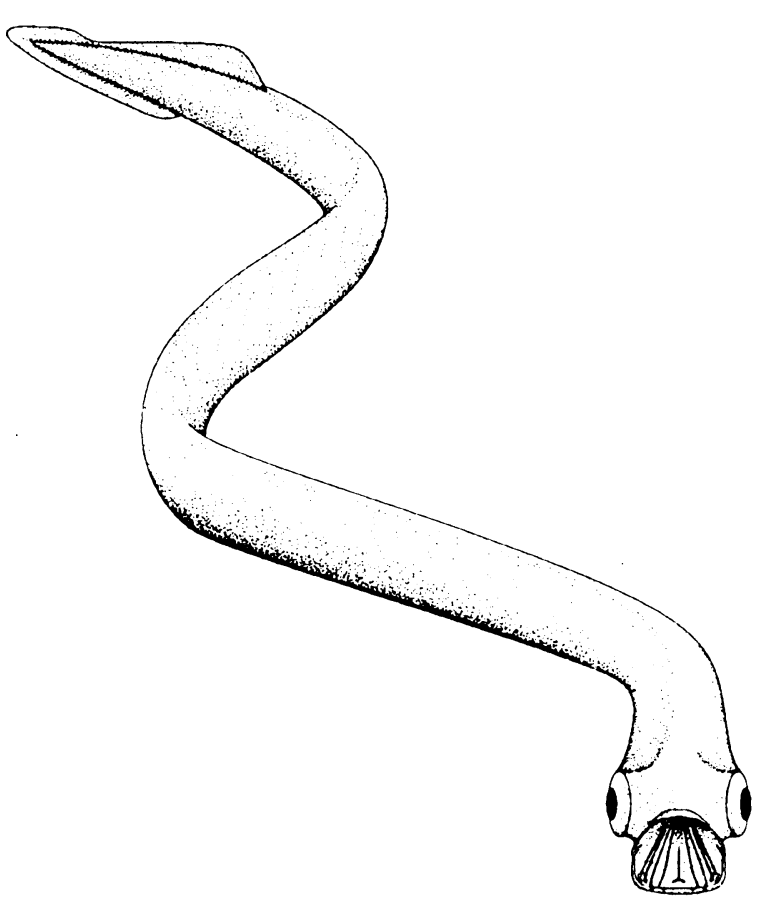

Ordovician Soom Shale and the Carboniferous Granton Shrimp Bed are similar. Conodont body shape, therefore, was probably highly conservative. The body was elongate and eel-like with a well developed tail fin, and conodonts must have been anguilliform swimmers. From estimates of maximum swimming speeds conodonts were probably not capable of sustained high-speed cruising or rapid acceleration, and they would not have been able to chase-down elusive prey.

The emerging picture is of conodonts as macrophagous, probably predatory animals equipped with an elaborate set of teeth and good vision. They were able to swim, but could not chase-down their food, and given that they were jawless they could not have employed suctionfeeding as a means of prey acquisition. These constraints on foraging strategies are probably reflected in the evolution of the most characteristic feature of conodonts, their complex dentition. This may be a unique adaptation for specialized mechanisms of ram-feeding. 